\title{
KOMPETENSI PROFESIONAL GURU SD NEGERI 43 MANDAU KABUPATEN BENGKALIS
}

\author{
Susanti $^{1}$, Zufriady ${ }^{2}$, Otang Kurniaman ${ }^{3}$ \\ 1,2,3 Universitas Riau, Pekanbaru, Indonesia \\ ${ }^{1}$ santisu9519@gmail.com, ${ }^{2}$ zufriady@lecturer.unri.ac.id, ${ }^{3}$ otang.kurniaman@lecturer.unri.ac.id
}

\begin{abstract}
ABSTRAK
Tujuan penelitian ini adalah untuk mendeskripsikan kompetensi profesional Guru SD Negeri 43 Mandau Kabupaten Bengkalis. Penelitian ini dilakukan di SD Negeri 43 Mandau Kabupaten Bengkalis pada September 2020. Jenis penelitian adalah kuantitatif yang memberikan gambaran tentang keadaan yang sedang berlangsung pada objek penelitian yaitu Kompetensi Profesional Guru SD Negeri 43 Mandau Kabupaten Bengkalis. Pengambilan sampel dalam penelitian ini dengan menggunakan teknik sampling jenuh. Sampel yang digunakan yaitu seluruh SD Negeri 43 Mandau Kabupaten Bengkalis yang berjumlah 16 orang guru. Teknik pengumpulan data yang digunakan adalah teknik angket melalui media google form dengan instrumen penelitian ini berupa pernyataan tentang kompetensi profesional guru dengan empat alternatif jawaban dengan jumlah 57 soal. Hasil penelitian menyimpulkan bahwa kompetensi professional guru SD Negeri 43 Mandau Kabupaten Bengkalis secara keseluruhan mencapai 80,91\% dengan kategori baik. Jumlah kompetensi inti yang memperoleh nilai pada interval 85-100 dengan kategori "Baik Sekali" berjumlah 1 kompetensi inti, jumlah kompetensi inti yang memperoleh nilai pada interval 70-84 dengan kategori "Baik" berjumlah 2 kompetensi inti, jumlah kompetensi inti yang memperoleh nilai pada interval 50-69 dengan kategori "Cukup" berjumlah 1 kompetensi inti, dan jumlah kompetensi inti yang memperoleh nilai pada interval 0-49 dengan kategori "Kurang" berjumlah 0 kompetensi inti.
\end{abstract}

Kata Kunci: kompetensi profesional guru

\section{TEACHERS' PROFESSIONAL COMPETENCE AT SD NEGERI 43 MANDAU BENGKALIS}

\section{ABSTRACT}

The purpose of this research was to describe teachers' professional competence at SD Negeri 43 Mandau Bengkalis. This research was conducted at SD Negeri 43 Mandau Bengkalis on September 2020. The type of this research was quantitative which provided the description about the current condition on the research objects. The samples in this research were selected by saturated sampling technique. The samples of this research were all teachers at SD Negeri 43 Mandau Bengkalis by 16 teachers. Data were collected through a questionnaire via google form containing the statements about teachers ' professional competence with four alternative answers for as many as 57 questions. The research results concluded that the teachers' professional competence at SD Negeri 43 Mandau Bengkalis reached 80,91\% with "Good" category. The number of core competency which scored in the interval 85-100 with the category of "Very Good" was 1 core competency, in the intervals of 70-84 with the category "Good" were 2 core competency, in the intervals of 50-69 with the category "Enough" was 1 core competency, and in the interval of 0-49 with the category "Less" was 0 core competency.

Keywords: teachers' professional competence

\begin{tabular}{|c|c|c|}
\hline Submitted & Accepted & Published \\
\hline 10 November 2020 & 22 April 2021 & 27 November 2021 \\
\hline
\end{tabular}

\begin{tabular}{|l|l|ccc|}
\hline Citation & $:$ & $\begin{array}{c}\text { Susanti, S., Zufriady, Z., \& Kurniaman, O. (2021). Kompetensi Profesional Guru SD Negeri } 43 \text { Mandau Kabupaten } \\
\text { Bengkalis. Jurnal PAJAR (Pendidikan dan Pengajaran), 5(6), 1740-1745. }\end{array}$ \\
& & Dttp://dx.doi.org/10.33578/pjr.v5i6.8210. \\
\hline
\end{tabular}

\section{PENDAHULUAN}

Guru adalah pendidik profesional dengan tugas utama yaitu mendidik, mengajar, membimbing, mengarahkan, melatih, menilai, dan mengevaluasi peserta didik pada pendidikan anak usia dini jalur pendidikan formal, pendidikan dasar, dan pendidikan menengah (UU No.14 Tahun 2005). Dalam dunia pendidikan, keberadaan peran dan fungsi guru sangat signifikan dalam usaha peningkatan mutu pendidikan. Syaiful Sagala (2009) menyatakan bahwa guru yang memenuhi standar adalah guru yang memenuhi kualifikasi yang disyaratkan dan memahami benar apa yang harus dilakukan, baik ketika di dalam kelas maupun di luar kelas.

Berdasarkan Permendiknas nomor 16 tahun 2007 tentang standar kompetensi 
professional yang harus dimiliki oleh guru, terdapat empat kompetensi yang harus dimiliki oleh guru, yaitu: kompetensi pedagogik, kompetensi professional, kompetensi sosial, dan kompetensi kepribadian. Kompetensi-kompetensi tersebut tidak dapat dipisah-pisahkan karena kompetensi tersebut berkaitan satu sama lain dan semua kompetensi harus dimiliki oleh seorang guru agar dapat menjadi guru yang profesional. Seorang guru yang berkompeten dapat menguasai dan melaksanakan kegiatan-kegiatan yang terdapat di dalam aspek-aspek kompetensi.

Beberapa penelitian sebelumnya telah banyak melakukan penelitian tentang profesionalitas guru menemukan bahwa guru yang profesional (memenuhi standar tenaga pendidik) dapat melaksanakan tugas dan fungsinya sebagai guru dengan maksimal (Nofrico Efendi, 2013). Peni Darmawan (2016) menyatakan bahwa guru secara mutlak harus mempunyai keempat kompetensi, yaitu kompetensi pedagogik, profesional, sosial dan kepribadian hal ini dikarenakan kesuksesan dalam proses pelaksanaan pendidikan ditentukan oleh guru yang professional.

Guru mempunyai peranan yang penting dalam proses pembelajaran karena guru tidak hanya menyampaikan materi pelajaran saja, tetapi guru juga memberikan pendidikan karakter kepada siswa, yaitu mendidik siswa menjadi warga negara yang 2 cerdas dan memiliki pribadi yang baik. Guru harus mengetahui dan dapat mengaplikasikan model dan metode pembelajaran yang inovatif dan menyenangkan. Pendidikan saat ini menuntut siswa untuk berpartisipasi aktif dalam proses pembelajaran. Sekarang ini sudah banyak model dan metode pembelajaran inovatif yang dapat membuat siswa berperan aktif, memperhatian, dan berkonsentrasi dalam mengikuti proses belajar mengajar.

Menurut Peraturan Menteri Pendidikan Nasional (Permendiknas) No.16 Tahun 2007 menjelaskan bahwa guru pada Sekolah Dasar atau Madrasah Ibtidaiyah (SD/MI), atau bentuk lain yang sederajat, harus memiliki kualifikasi akademik pendidikan minimum diploma empat (D-IV) atau sarjana (S1) dalam bidang pendidikan Sekolah Dasar atau Madrasah Ibtidaiyah (D-IV/S1 PGSD/MI) atau psikologi yang diperoleh dari program studi yang terakreditasi, sedangkan standar uji kompetensi profesional guru dikembangkan dari Permendiknas No.16 Tahun 2007 tentang standar kualifikasi akademik dan kompetensi guru secara utuh dari empat indikator inti kompetensi profesional yaitu: (a) menguasai standar kompetensi dan kompetensi dasar mata pelajaran/bidang pengembangan yang diampu; (b) mengembangkan materi pembelajaran yang diampu secara kreatif; (c) mengembangkan keprofesionalan 4 secara berkelanjutan dengan melakukan tindakan reflektif; dan (d) memanfaatkan teknologi informasi dan komunikasi untuk berkomunikasi dan mengembangkan diri.

Berdasarkan keterangan dari kepala sekolah SD Negeri 43 Mandau diketahui bahwa meskipun guru-guru telah mengetahui berbagai model dan metode pembelajaran yang kreatif dan inovatif, tetapi guru-guru masih dominan menggunakan metode ceramah dalam menyampaikan pelajaran, guru seharusnya juga dapat menerapkan metode lain yang lebih kreatif. Guru juga belum mampu mengembangkan silabusnya sendiri, karena guru masih menggunakan silabus yang diadopsi dari hasil KKG dan berbagai sumber. Hampir semua guru sudah dapat menyusun rencana pelaksanaan pembelajaran (RPP) sendiri, tetapi ada juga guru yang menggunakan RPP tahun lalu untuk pelaksanaan pembelajaran pada tahuntahun selanjutnya.

\section{METODE PENELITIAN}

Penelitian ini telah dilaksanakan di SD Negeri 43 Mandau Kabupaten Bengkalis pada bulan September 2020. Jenis penelitian adalah kuantitatif. Sugiyono (2013) menyatakan bahwa penelitian kuantitatif merupakan penelitian yang berlandaskan pada filsafat positivisme, digunakan untuk meneliti pada populasi atau sampel tertentu, pengumpulan data menggunakan instrumen penelitian, analisis data bersifat kuantitatif/statistik. Penelitian bertujuan untuk mendeskripsikan yaitu memberikan gambaran tentang keadaan yang sedang berlangsung pada objek penelitian yaitu tentang kompetensi profesional guru SD Negeri 43 Mandau Kabupaten Bengkalis. Pengambilan sampel dalam penelitian 
ini menggunakan teknik sampling jenuh. Sampel yang digunakan yaitu seluruh guru SD Negeri 43 Mandau Kabupaten Bengkalis yang berjumlah 16 orang guru. Data dalam penelitian ini adalah data tentang kompetensi profesional guru diambil langsung dari guru SD Negeri 43 Mandau Kabupaten Bengkalis yaitu 16 orang guru. Data ini dikumpulkan dengan menggunakan angket melalui media google form mengenai kompetensi profesional guru.

Teknik analisis data yang digunakan melalui beberapa tahapan yaitu: uji validitas, uji reliabilitas data dan selanjutnya mengolah data dengan menggunakan rumus persentase sebagai berikut:

Keterangan:

$$
\mathrm{N}=\frac{F}{S} \times 100 \%
$$

$\begin{array}{ll}\mathrm{N} & \text { : Nilai yang diperoleh } \\ \mathrm{F} & \text { : Jumlah skor didapat }\end{array}$
S : Jumlah skor maksimal

100 : Bilangan tetap

Sumber: Akson dan Sahlan (2005)

\section{HASIL DAN PEMBAHASAN}

Setelah data kompetensi profesional guru diolah, selanjutnya penyajian hasil penelitian tentang kompetensi profesional guru SD Negeri 43 Mandau Kabupaten Bengkalis secara detail pada setiap indikator pada empat kompetensi inti pada kompetensi profesional. Adapun hasil penelitian tentang perolehan data kompetensi profesional adalah sebagai berikut.

\section{Kompetensi Profesional Guru SD Negeri 43 Mandau Kabupaten Bengkalis}

Adapun perolehan data tentang kompetensi profesional guru SD Negeri 43 Mandau Kabupaten Bengkalis.

Tabel 1. Kompetensi Profesional Guru SD Negeri 43 Mandau Kabupaten Bengkalis

\begin{tabular}{cccccc}
\hline Interval & Kategori & $\begin{array}{c}\text { Jumlah } \\
\text { Guru }\end{array}$ & $\begin{array}{c}\text { Jumlah Guru } \\
\text { Keseluruhan }\end{array}$ & $\begin{array}{c}\text { Rata- } \\
\text { rata }\end{array}$ & Ketegori \\
\hline $85-100$ & Baik Sekali & 1 & & & \\
$70-84$ & Baik & 2 & \multirow{2}{*}{ Baik } \\
$50-69$ & Cukup & 1 & & $80.91 \%$ & \\
$0-49$ & Kurang & 0 & & & \\
\hline
\end{tabular}

Berdasarkan tabel di atas, diketahui bahwa jumlah guru yang memperoleh nilai pada interval 85-100 dengan kategori "Baik Sekali" berjumlah 1 guru, jumlah guru yang memperoleh nilai pada interval 70-84 dengan kategori "Baik" berjumlah 2 guru, jumlah guru yang memperoleh nilai pada interval 50-69 dengan kategori "Cukup" berjumlah 1 guru, dan jumlah guru yang memperoleh nilai pada interval 0-49 dengan kategori "Kurang" berjumlah 0 guru. Rata-rata perolehan nilai kompetensi pedagogik guru sebesar 87.62\% dengan kategori "Baik Sekali".

\section{Analisis Per-Indikator Kompetensi Profesional Guru SD Negeri 43 Mandau Kabupaten Bengkalis \\ Berdasarkan Permendiknas No. 16}

Tahun 2007 tentang standar kompetensi guru SD/MI menyatakan bahwa kompetensi profesional terdiri dari 4 kompetensi inti. Adapun perolehan hasil per-indikator tentang kompetensi profesional dapat dilihat pada tabel 2 di bawah ini.

Tabel 2. Kompetensi Profesional Guru SD Negeri 43 Mandau Kabupaten Bengkalis PerKompetensi Inti

\begin{tabular}{|c|c|c|c|}
\hline No & Kompetensi Inti & Persentase & Kategori \\
\hline 1 & $\begin{array}{l}\text { Menguasai standar kompetensi dan } \\
\text { kompetensi dasar mata pelajaran/bidang } \\
\text { pengembangan vang diampu. }\end{array}$ & 88.93 & Baik Sekali \\
\hline
\end{tabular}




\begin{tabular}{llll}
\hline 2 & $\begin{array}{l}\text { Mengembangkan materi pembelajaran yang } \\
\text { diampu secara kreatif. }\end{array}$ & 83.21 & Baik \\
\hline 3 & $\begin{array}{l}\text { Mengembangkan keprofesionalan secara } \\
\text { berkelanjutan dengan melakukan tindakan } \\
\text { reflektif. }\end{array}$ & 68.8 & Cukup \\
\hline & $\begin{array}{l}\text { Memanfaatkan teknologi informasi dan } \\
\text { komunikasi untuk berkomunikasi dan } \\
\text { mengembangkan diri. }\end{array}$ & 82.73 & Baik \\
\hline
\end{tabular}

Menguasai Standar Kompetensi dan Kompetensi Dasar Mata Pelajaran/Bidang Pengembangan yang Diampu

Data penelitian mengenai kompetensi profesional guru dalam menguasai karakteristik peserta didik dari aspek fisik, moral, sosial, kultural, emosional, dan intelektual terdiri dari 3 indikator yaitu (a) memahami standar kompetensi mata pelajaran yang diampu, (b) memahami kompetensi dasar mata pelajaran yang diampu, dan (c) memahami tujuan pembelajaran yang diampu.

Adapun perolehan data pada masingmasing indikator di atas dapat dilihat pada tabel 3 di bawah ini.

Tabel 3. Kompetensi Profesional Guru pada Kompetensi Menguasai Standar Kompetensi dan Kompetensi Dasar Mata Pelajaran/Bidang Pengembangan yang Diampu

\begin{tabular}{ccccccc}
\hline No & Keterangan & Jumlah Soal & Persentase & Rata-rata & Kategori & $\begin{array}{c}\text { Jumlah } \\
\text { Responden }\end{array}$ \\
\hline 1 & Indikator 1 & 2 & 100 & & Baik & 16 \\
2 & Indikator 2 & 3 & 87.53 & 88.93 & Sekali & \\
3 & Indikator 3 & 4 & 84.45 & & \\
\hline
\end{tabular}

\section{Mengembangkan Materi Pembelajaran yang Diampu Secara Kreatif}

Data penelitian mengenai kompetensi profesional guru dalam Mengembangkan materi pembelajaran yang diampu secara kreatif terdiri dari 2 indikator yaitu (a) memilih materi pembelajaran yang diampu sesuai dengan tingkat perkembangan peserta didik, dan (b) mengolah materi pelajaran yang diampu secara kreatif sesuai dengan tingkat perkembangan peserta didik. berbagai teori belajar dan prinsip-prinsip pembelajaran yang mendidik terkait dengan lima mata pelajaran SD/MI.

Adapun perolehan data pada masingmasing indikator di atas dapat dilihat pada tabel 4 di bawah ini.

Tabel 4. Kompetensi Profesional Guru pada Kompetensi Mengembangkan Materi Pembelajaran yang Diampu Secara Kreatif

\begin{tabular}{ccccccc}
\hline No & Keterangan & Jumlah Soal & Persentase & Rata-rata & Kategori & $\begin{array}{c}\text { Jumlah } \\
\text { Responden }\end{array}$ \\
\hline 1 & Indikator 1 & 7 & 77.71 & \multirow{2}{*}{ Baik } & 16 \\
2 & Indikator 2 & 6 & 89.63 & & \\
\hline
\end{tabular}


Mengembangkan Keprofesionalan Secara Berkelanjutan dengan Melakukan Tindakan Reflektif

Data penelitian mengenai kompetensi pedagogik guru dalam mengembangkan keprofesionalan secara berkelanjutan dengan melakukan tindakan reflektif terdiri dari 4 indikator yaitu (a) melakukan refleksi terhadap kinerja sendiri secara terus menerus, (b) memanfaatkan hasil refleksi dalam rangka peningkatan keprofesionalan, (c) melakukan penelitian tindakan kelas untuk peningkatan keprofesionalan, dan (d) mengikuti kemajuan zaman dengan belajar dari berbagai sumber.

Adapun perolehan data pada masingmasing indikator di atas dapat dilihat pada tabel 5 di bawah ini.

Tabel 5. Kompetensi Profesional Guru pada Kompetensi Mengembangkan Keprofesionalan Secara Berkelanjutan dengan Melakukan Tindakan Reflektif

\begin{tabular}{|c|c|c|c|c|c|c|}
\hline No & Keterangan & Jumlah Soal & Persentase & Rata-rata & Kategori & $\begin{array}{c}\text { Jumlah } \\
\text { Responden }\end{array}$ \\
\hline 1 & Indikator 1 & 12 & 61.50 & \multirow{4}{*}{68.8} & \multirow{4}{*}{ Cukup } & \multirow{4}{*}{16} \\
\hline 2 & Indikator 2 & 4 & 75.05 & & & \\
\hline 3 & Indikator 3 & 3 & 70.86 & & & \\
\hline 4 & Indikator 4 & 3 & 87.56 & & & \\
\hline
\end{tabular}

Memanfaatkan Teknologi Informasi dan Komunikasi Untuk Berkomunikasi dan Mengembangkan Diri

Data penelitian mengenai kompetensi profesional guru dalam memanfaatkan teknologi informasi dan komunikasi untuk berkomunikasi dan mengembangkan diri terdiri dari 2 indikator yaitu (a) memanfaatkan teknologi informasi dan komunikasi dalam berkomunikasi, dan (b) memanfaatkan teknologi informasi dan komunikasi untuk pengembangan diri.

Adapun perolehan data pada masingmasing indikator di atas dapat dilihat pada tabel 6 di bawah ini.

Tabel 6. Kompetensi Profesional Guru pada Kompetensi Memanfaatkan Teknologi Informasi dan Komunikasi Untuk Berkomunikasi dan Mengembangkan Diri

\begin{tabular}{ccccccc}
\hline No & Keterangan & Jumlah Soal & Persentase & Rata-rata & Kategori & $\begin{array}{c}\text { Jumlah } \\
\text { Responden }\end{array}$ \\
\hline 1 & Indikator 1 & 5 & 95.04 & & & 16 \\
2 & Indikator 2 & 8 & 75.05 & 82.73 & Baik & \\
\hline
\end{tabular}

\section{SIMPULAN DAN REKOMENDASI}

Berdasarkan hasil penelitian dan pembahasan, maka penelitian ini dapat disimpulkan bahwa kompetensi profesional Guru SD Negeri 43 Mandau Kabupaten Bengkalis termasuk dalam kategori baik. Hal ini dibuktikan dengan perolehan data kompetensi profesional oleh guru, yaitu rata-rata perolehan nilai kompetensi profesional guru sebesar $80.91 \%$ dengan kategori "Baik". Jumlah kompetensi inti yang memperoleh nilai pada interval 85-100 dengan kategori "Baik Sekali" berjumlah 1 kompetensi inti, yaitu: (1) kompetensi inti kesatu tentang "Menguasai standar kompetensi dan kompetensi dasar mata pelajaran/bidang pengembangan yang diampu" dengan perolehan persentase sebesar $88.93 \%$. Jumlah kompetensi inti yang memperoleh nilai pada interval 70-84 dengan kategori "Baik" berjumlah 2 kompetensi inti, yaitu: (1) kompetensi inti kedua tentang "Mengembangkan materi pembelajaran yang diampu secara kreatif" dengan perolehan persentase sebesar $83.21 \%$; dan (2) kompetensi inti keempat tentang "Memanfaatkan teknologi 
informasi dan komunikasi untuk berkomunikasi dan mengembangkan diri" dengan perolehan persentase sebesar $82.73 \%$. Dan jumlah kompetensi inti yang memperoleh nilai pada interval 50-69 dengan kategori "Cukup" berjumlah 1 kompetensi inti, yaitu: (1) kompetensi inti ketiga tentang "Mengembangkan keprofesionalan secara berkelanjutan dengan melakukan tindakan reflektif" dengan perolehan persentase sebesar $68.8 \%$.

Adapun rekomendasi yang ingin peneliti sampaikan sehubungan dengan kompetensi profesional guru yaitu:

1. Sebaiknya guru-guru terus meningkatkan lagi kualitas kompetensi profesional yang dimiliki dan selalu mengembangkan kemampuan diri agar tercapainya kualitas pendidikan dan terbentuknya peserta didik yang lebih baik serta berkualitas.

2. Untuk peneliti selanjutnya yang akan melakukan penelitian yang sejenis untuk menambahkan atau menggunakan lembar observasi dan wawancara agar memperoleh hasil yang lebih mendalam tentang kompetensi profesional guru.

\section{DAFTAR PUSTAKA}

Akson dan Sahlan. (2005). Aplikasi Statistika dan Metode Penelitiain untuk Administrasi dan Manajemen. Bandung: Dewa Ruci.

Antonius. (2016). Buku Pedoman Guru. Bandung: Yrama Widya.

Arikunto, S. (2014). Prosedur Penelitian, Suatu Pendekatan Praktik. Jakarta: PT Rineka Cipta.

Asmara, H. (2015). Profesi Kependidikan. Bandung: Alfabeta.

Darmawan, P. (2016). Analisis Kompetensi Profesional Guru Sekolah Dasar Negeri Gugus II Kecamatan Marpoyan Damai Kota Pekanbaru. Jurnal Online Mahasiswa FKIP Univeritas Riau. (Online).

https://jom.unri.ac.id/index.php/JOMFKI

$\mathrm{P} /$ issue/view/364. (Diakses pada tanggal 20 Juni 2020)

Efendi, N. (2013). Analisis Profesionalitas Guru Sekolah Dasar Se-Kecamatan Tampan Kota Pekanbaru. Jurnal Online
Mahasiswa FKIP Univeritas Riau.

(Online).

https://jom.unri.ac.id/index.php/JOMFKI

$\mathrm{P} /$ issue/view/217. (Diakses pada tanggal 28 Juli 2020)

Huda, M. N. (2018). Kompetensi Pedagogik Mahasiswa Program Studi Pendidikan Guru Sekolah Dasar. Jurnal Online Mahasiswa FKIP Universitas Riau. (Online).

https://jom.unri.ac.id/index.php/JOMFKI

P/article/view/17835/17226. (Diakses pada tanggal 20 Juni 2020)

Kuncoro, N. W. (2013). Hubungan Kompetensi Profesional Guru dengan Hasil Belajar IPS Siswa. Portal Garuda. (Online). http://download.portalgaruda.org/article.p hp? article $=288944 \&$ val $=7239 \&$ title $=H$ UBUNGAN\%20KOMPETENSI\%20PED AGOGIK\%20GURU\%20DENGAN\% 20HASIL\%20BELAJAR\%20IPS\%20SIS WA. (Diakses pada tanggal 28 Juli 2020)

Kurniasih, I., dan Berlin, S. (2015). Sukses Uji Kompetensi Guru Panduan lengkap. Surabaya: Kata Pena.

Kurniasih, I dan Berlin, S. (2017). Kupas Tuntas Kompetensi Pedagogik Teori dan Praktik. Surabaya: Kata Pena.

Mulyasa. (2007). Menjadi Guru Profesional, Menciptakan Pembelajaran Kreatif dan Menyenangkan. Bandung: PT. Remaja Rosdakarya.

Mulyasa. (2012). Standar Kompetensi dan Sertifikasi Guru. Bandung: PT Remaja Rosdakarya.

Slameto. (2003). Belajar dan Faktor-Faktor yang mempengaruhinya. Jakarta: Rineka Cipta.

Sugiyono. (2013). Metode Penelitian Kuantitatif Kualitatif dan $R \& D$. Bandung: Alfabeta.

Sumirat, F. (2015). Analisis Kompetensi Guru Sekolah Dasar Dalam Mengembangkan Kurikulum dan Rancangan Pembelajaran SD Ar-Rafi' Kota Bandung. Jurnal Universitas Islam 45.3:2035.Universitas Islam 45. Bekasi.

Zulfah. (2016). 99,9\% Lulus UjiKompetensi Guru $(U K G)$. Yogyakarta: Bright Publisher. 